\title{
$\varnothing$ EDITOR'S CHOICE \\ Adherence to asthma management guidelines by middle-aged adults with current asthma
}

\author{
R K Kandane-Rathnayake, ${ }^{1}$ M C Matheson, ${ }^{1}$ J A Simpson, ${ }^{1,2}$ M L K Tang, ${ }^{3,4}$ D P Johns, ${ }^{5}$ \\ D Mészáros, ${ }^{5} \mathrm{R}$ Wood-Baker, ${ }^{5}$ I Feather, ${ }^{6} \mathrm{~S}$ Morrison, ${ }^{7} \mathrm{M}$ A Jenkins, ${ }^{1} \mathrm{G}$ G Giles, ${ }^{1,2}$ \\ J Hopper, ${ }^{1}$ M J Abramson, ${ }^{8}$ S C Dharmage, ${ }^{1}$ E H Walters ${ }^{1,5,8}$
}

${ }^{1}$ Centre for Molecular, Environmental, Genetic and Analytic Epidemiology, University of Melbourne, Melbourne, Australia; ${ }^{2}$ Cancer Epidemiology Centre, The Cancer Council Victoria, Melbourne, Australia; ${ }^{3}$ Department of Allergy and Immunology, Murdoch Children's Research Institute, Royal Children's Hospital Melbourne, Australia; ${ }^{4}$ Department of Paediatrics, University of Melbourne, Melbourne,

Australia; ${ }^{5}$ Menzies Research Institute, Tasmania, Australia;

${ }^{6}$ Gold Coast Hospital,

Queensland, Australia;

${ }^{7}$ University of Queensland,

Queensland, Australia;

${ }^{8}$ Epidemiology and Preventive

Medicine, Monash University,

Melbourne, Australia

Correspondence to:

Ms R Kandane-Rathnayake,

Centre for Molecular,

Environmental, Genetic and

Analytic Epidemiology,

Department of Public Health,

School of Population Health, The

University of Melbourne, Level

1/723 Swanston Street, Carlton,

Victoria 3053, Australia;

r.kandane@pgrad.unimelb.edu.au

Received 23 April 2009

Accepted 17 July 2009

Published Online First

23 August 2009

\begin{abstract}
Background: With the increasing burden of asthma worldwide, much effort has been given to developing and updating management guidelines. Using data from the Tasmanian Longitudinal Health Study (TAHS), the adequacy of asthma management for middle-aged adults with asthma was investigated.

Methods: Information about spirometry, medication history and current asthma status was collected by the most recent TAHS when participants were in their mid 40s. Only those who reported ever having asthma were eligible for analysis.
\end{abstract}

Results: Of the 702 participants who reported ever having asthma, $50 \%$ had current asthma $(n=351)$ of whom $71 \%$ were categorised as having persistent asthma ( $n=98$ mild, $n=92$ moderate, $n=58$ severe). The majority (85.2\%) of participants with current asthma had used some form of asthma medication in the past 12 months, but the proportion of the use of minimally adequate preventer medication was low (26\%). Postbronchodilator airflow obstruction increased progressively from mild to severe persistent asthma for those inadequately managed, but not for those on adequate therapy.

Conclusion: Appropriate use of asthma medication by this middle-aged group of adults with current asthma was inadequate, especially for those with adult-onset moderate or severe persistent disease and without a family history of asthma. These results suggest that proper use of preventer medication could protect against the progressive decline in lung function associated with increasing severity. This has implications not just for poor quality of life, but also for the development of fixed airflow obstruction.

Asthma is a chronic inflammatory disorder of the airways that affects people of all ages. According to the European Community Respiratory Health Survey (ECRHS), the prevalence of adult asthma across 22 countries ranged from $2 \%$ to $12 \% .{ }^{1}$ In Australia the prevalence of current adult asthma was estimated to be $10.2 \%$ (95\% CI $9.1 \%$ to $13.0 \%$, which represents more than 2 million people. The national expenditure on asthma care for 2004-5 was over Australian 600 million dollars or $1.2 \%$ of the health budget. ${ }^{2}$

With such a high burden of asthma, national and international guidelines have been produced and frequently updated to provide strategies for better asthma management and treatment. Australia's national guidelines are evidence-based and included in the National Asthma Council's (NAC) Asthma Management Handbook, which was last updated in 2006. ${ }^{3}$ Other international asthma guidelines include the United States National Asthma Education and Prevention Program (NAEPP) ${ }^{4}$ and the Global Initiative for Asthma (GINA). ${ }^{5}$ Assessments of how well such guidelines are followed in the community remain sparse and there has been little audit of actual patient behaviours and how these affect outcomes. ${ }^{6-8}$

According to all asthma guidelines, evaluation of severity is necessary for appropriate and adequate treatment, especially the selection and dosing of medication. ${ }^{35}$ It is also essential to monitor the effect of treatment, including symptoms and lung function, in order to titrate treatment. Of the medications available for asthma control, inhaled glucocorticosteroids (ICS), used alone or in combination with long-acting $\beta$ agonists (LABA), are known to be the most effective ${ }^{910}$ and are recommended as the first-line treatment for persistent asthma. ${ }^{11}$

Despite guideline recommendations, the limited audits available suggest that control of persistent asthma by adequate use of medication remains poor. ${ }^{12-14}$ In 2005, De Marco et al investigated the adequacy of anti-inflammatory therapy use in Italy for a population with current asthma as defined by GINA guidelines. ${ }^{12}$ They reported that $48 \%$ of their study population with persistent asthma were using inadequate treatment. Similarly, a recent study from Saskatchewan, Canada reported that, for asthma patients with poor control, $37 \%$ had not used any ICS, $40 \%$ had used inadequate doses and only $23 \%$ had received adequate preventer medication. ${ }^{15}$

Cross-sectional audits of asthma management in Australia have found it to be suboptimal. ${ }^{13} 14$ However, evidence for how well asthma medication regimens are being used by patients with asthma, as recommended by the NAC in relation to severity in Australia, is not available. In this analysis we have assessed how well asthma has been managed with medications as recommended by NAC guidelines for a middle-aged asthma population who are part of the Tasmanian Longitudinal Health Study (TAHS), which is a cohort followed up for over four decades. The NAC guidelines are quite consistent with most others internationally, and our conclusions are likely to be widely applicable.

We examined the adequacy of preventer medication in relation to asthma severity and other factors using participants with current asthma from an Australian community-based study. We 
also examined the effect of adequacy of treatment on postbronchodilator (BD) fixed airflow obstruction. Asthma severity and "minimal adequacy" of medication were defined according to NAC guidelines.

\section{METHODS}

\section{Study design}

This analysis is based on a subgroup selected from the most recent laboratory study of the TAHS. The details of the methodology and some results from this study have been reported elsewhere. ${ }^{16-20}$ In brief, TAHS commenced in 1968 by recruiting 8583 Tasmanian children born in 1961, who were surveyed for respiratory problems and underwent clinical examination and lung function measurements. Subsequent follow-up surveys were completed at the ages of 13 (in 1974), 20 (in 1981) and 31 (in 1992). The current follow-up started in 2004 when the probands were 44 years of age. We have traced $85.2 \%(n=7312)$ of the original 1968 cohort to an address and achieved a response of $78.4 \%(n=5729)$ to a postal survey. ${ }^{20} \mathrm{~A}$ subgroup of these respondents were selected based on their participation in the previous follow-up studies, samples of which were enriched for asthma, and invited to participate in a more detailed laboratory study. Of 2373 invited, 1389 (58.5\%) took part in a full laboratory visit, $354(15 \%)$ completed a telephone questionnaire only and 630 (26.5\%) withdrew.

\section{Questionnaires and clinical tests}

During the laboratory phase of the study, participants completed an interview-administered questionnaire which captured information about their demographics and, where relevant, details of their asthma (past and present), smoking history, medication use and healthcare service utilisation.

\section{Lung function testing}

Lung function was measured with an Easyone ultrasonic spirometer (ndd, Medizintechnik, AG, Switzerland). Participants were asked not to smoke for 4-6 h prior to testing. Forced expiratory volume in $1 \mathrm{~s}\left(\mathrm{FEV}_{1}\right)$ was recorded as the best of three blows that met American Thoracic Society criteria. ${ }^{21}$ Predicted values for $\mathrm{FEV}_{1}$ and forced vital capacity (FVC) were calculated from age, height and gender using equations by Gore et al. ${ }^{22}$ Spirometry was repeated $10 \mathrm{~min}$ after $200 \mu \mathrm{g}$ (2 puffs) of salbutamol administered via a spacer.

\section{Definitions}

\section{Current asthma}

Asthma-ever was defined as a positive response by participants in the current laboratory follow-up to the question "Have you ever had asthma?" Participants were defined as having current asthma if they had experienced symptoms within the last 12 months.

\section{Asthma severity and minimal adequate medication}

The definition of asthma severity was adopted from the NAC classification of asthma for patients with untreated newly diagnosed asthma and based on self-reported morning, daytime and night-time symptoms and number of flare-ups (table 1). Similarly, the minimum level of adequate preventer medication was defined according to the NAC guidelines and the medication regimens used here were essentially the minimum level of treatment recommended to be prescribed at initial assessment by a physician at a particular level of current severity.

\section{Onset of current asthma}

Participants with current asthma were defined as having "earlyonset current asthma" or "late-onset current asthma" based on asthma data from the 1968, 1974 and 2004 surveys. If the participants with current asthma had reported either ever asthma in 1968 or current asthma in 1974 or both, they were classified as having early-onset current asthma. If the participants had current asthma in 2004 but had no ever asthma recorded in 1968 or 1974, they were classified as having lateonset current asthma.

\section{Statistical analysis}

All statistical analyses were performed using Stata version 9 (StataCorp, College Station, Texas, USA). The distributions of personal characteristics such as gender, smoking status, family history and level of education across the asthma severity groups were examined using $\chi^{2}$ tests. We also performed multiple logistic regression analyses to examine the associations between these personal characteristics and adequacy of preventer medication use by participants with current asthma. In addition, we performed multiple linear regressions to assess the relationships between lung function measurements and adequate preventer medication use while accounting for the asthma severity. We further stratified these associations by the adequacy groups to investigate any variation in the association between adequacy of medication and lung function across the severity groups. All multiple linear regression models were adjusted for gender, smoking status, age, weight and height. A p value of $<0.05$ was regarded as statistically significant.

\section{RESULTS}

Personal characteristics of the participants by asthma severity In total, 702 participants reported asthma ever and, of these, $351(50 \%)$ had current asthma. Of those with current asthma, $103(29.3 \%)$ had intermittent asthma, 98 (27.9\%) had mild persistent asthma, $92(26.2 \%)$ had moderate persistent asthma and $58(16.5 \%)$ had severe persistent asthma. The distribution

Table 1 Definitions of severity based on self-reported symptoms and recommended minimum preventer therapy

\begin{tabular}{|c|c|c|}
\hline Severity & $\begin{array}{l}\text { Frequency of self-reported } \\
\text { symptoms* }\end{array}$ & $\begin{array}{l}\text { Minimum adequate } \\
\text { preventer medication }\end{array}$ \\
\hline $\begin{array}{l}\text { Asymptomatic } \\
\text { asthma }\end{array}$ & $\begin{array}{l}\text { No symptoms last year but on } \\
\text { asthma medication }\end{array}$ & None \\
\hline Intermittent asthma & $\begin{array}{l}\text { Symptoms in the last year but not } \\
\text { in the last month, } \leqslant 3 \text { flare-ups in } \\
\text { the last year }\end{array}$ & None $\uparrow$ \\
\hline $\begin{array}{l}\text { Mild persistent } \\
\text { asthma }\end{array}$ & $\begin{array}{l}\text { Symptoms in the last month but } \\
\text { less than weekly, } \geqslant 4 \text { flare-ups in } \\
\text { the last year but less than } \\
\text { monthly }\end{array}$ & $\begin{array}{l}\text { ICS alone low dose } \\
(200 \mu \mathrm{g} \mathrm{BDP} / 160 \mu \mathrm{g} \mathrm{CIC/} \\
200 \mu \mathrm{g} \mathrm{FP} / 400 \mu \mathrm{g} \text { BUD }) \\
\text { daily }\end{array}$ \\
\hline $\begin{array}{l}\text { Moderate persistent } \\
\text { asthma }\end{array}$ & $\begin{array}{l}\text { Symptoms more than once } \\
\text { weekly but not daily, flare-ups } \\
\text { more than monthly in the last year }\end{array}$ & $\begin{array}{l}\text { ICS }(200 \mu \mathrm{g} \text { BDP/400 } \mu \mathrm{g} \\
\mathrm{BDP} / 160-320 \mu \mathrm{g} \mathrm{CIC} / \\
200-400 \mu \mathrm{g} \mathrm{FP} / 400- \\
800 \mu \mathrm{g} \text { BUD) plus LABA } \\
\text { daily }\end{array}$ \\
\hline $\begin{array}{l}\text { Severe persistent } \\
\text { asthma }\end{array}$ & $\begin{array}{l}\text { Symptoms daily and flare-ups } \\
\text { more than weekly in the last year }\end{array}$ & $\begin{array}{l}\text { High dose of ICS } \\
(>400 \mu \mathrm{gDP} />320 \mu \mathrm{g} \\
\mathrm{CIC} />400 \mu \mathrm{g} \\
\mathrm{FP} />800 \mu \mathrm{g} \text { BUD) daily }\end{array}$ \\
\hline
\end{tabular}

$\mathrm{BDP}$, beclomethasone dipropionate HFA aerosol; BUD, budesonide; $\mathrm{CIC}$, ciclesonide; FP, fluticasone propionate; ICS, inhaled corticosteroid; LABA, long-acting $\beta_{2}$ agonist. *Self-reported symptoms of (1) morning, (2) daytime, (3) night-time symptoms and (4) number of flare-ups.

$\uparrow$ Participants with intermittent asthma who were on preventer medication were categorised as "adequate preventer medication users" since, according to the NAC guidelines, they did not require being on preventer therapy. 
of relevant personal characteristics by severity groups is shown in table 2. The distributions of the proportions of women, the proportions of those with allergic conditions and those with parents and/or siblings with asthma across the severity groups were found to be statistically significant. On the other hand, distributions of level of education and smoking across the severity groups were not statistically significant, even though it was notable that over $40 \%$ of the patients with severe persistent asthma were current smokers.

\section{Asthma medication use by current asthma participants}

Approximately $85 \%$ of participants with current asthma had used some form of asthma medication in the past 12 months. A breakdown of the types of medications used is presented in table 2. Overall, the majority of participants with current asthma had used reliever medication (78\%, $\mathrm{n}=274)$. Only $16 \%$ $(n=55)$ had used ICS alone and 26\% $(n=93)$ had used a combination of ICS and LABA medication. In addition, four individuals were taking LABA alone, including one with severe asthma (table 2).

\section{Lung function levels and severity of asthma}

Lung function for participants with current asthma was significantly lower than for those who did not have current asthma. The mean $\mathrm{FEV}_{1}$ pre-BD for the participants with current asthma was 2.991 compared with 3.261 in participants with non-current asthma (mean difference -0.271 (95\% CI -0.36 to -0.17$), p<0.001)$. Similarly, post-BD FEV $1 / F V C$ in the participants with current asthma was $75.2 \%$ compared with $79.4 \%$ for those with non-current asthma (mean difference $-4.20 \%$ units $(95 \%$ CI $-5.52 \%$ to $-2.87 \%$ ), $p<0.001)$. Lung function measurements stratified by current asthma severity are summarised in table 3. Lung function was significantly associated with increasing severity (table 3 ). In participants with severe persistent asthma, pre-BD $\mathrm{FEV}_{1}$ was 0.31 lower than in participants with mild persistent asthma (95\% CI -0.52 to $-0.07, p=0.011$.

\section{Adequacy of preventer medication and its determinants}

Of the 351 participants with current asthma, only 26\% were taking minimally adequate preventer medication. We found that participants with current asthma who had family members with a history of asthma were more likely to use adequate preventer medication (table 4). Moreover, adequate preventer medication users were more likely to have visited general practitioner/casualty/hospital admission in the last year. Univariate logistic regression analysis showed that participants with early-onset asthma were more likely to use adequate

Table 2 Personal characteristics and medication use in community-based current asthma population by severity $(n=351)$

\begin{tabular}{|c|c|c|c|c|c|}
\hline & $\begin{array}{l}\text { Intermittent } \\
(\mathrm{n}=103)\end{array}$ & $\begin{array}{l}\text { Mild persistent } \\
(\mathrm{n}=\mathbf{9 8})\end{array}$ & $\begin{array}{l}\text { Moderate persistent } \\
(\mathrm{n}=92)\end{array}$ & $\begin{array}{l}\text { Severe persistent } \\
(\mathrm{n}=58)\end{array}$ & $\begin{array}{l}\text { Total } \\
(\mathrm{n}=351)\end{array}$ \\
\hline \multicolumn{6}{|l|}{ Personal characteristics } \\
\hline Female gender & $58(56.3 \%)$ & $58(59.2 \%)$ & $59(64.1 \%)$ & $30(51.7 \%)$ & $166(47.3 \%)$ \\
\hline \multicolumn{6}{|l|}{ Smoking status } \\
\hline Never & $47(45.6 \%)$ & $46(46.9 \%)$ & $38(41.3 \%)$ & $22(37.9 \%)$ & $143(40.7 \%)$ \\
\hline Past & $34(33.0 \%)$ & $28(28.6 \%)$ & $22(23.9 \%)$ & $12(20.7 \%)$ & $106(30.2 \%)$ \\
\hline Current & $22(21.4 \%)$ & $24(24.5 \%)$ & $32(34.8 \%)$ & $24(41.4 \%)$ & $102(29.1 \%)$ \\
\hline \multicolumn{6}{|l|}{ Level of education* } \\
\hline University degree & $24(23.5 \%)$ & $16(16.3 \%)$ & $13(14.3 \%)$ & $12(20.7 \%)$ & $70(20.2 \%)$ \\
\hline Trade/apprenticeship & $31(30.4 \%)$ & $41(41.8 \%)$ & $26(28.6 \%)$ & $22(37.9 \%)$ & $131(37.9 \%)$ \\
\hline Grade 10/11 & $41(40.2 \%)$ & $35(35.7 \%)$ & $41(45.1 \%)$ & $17(29.3 \%)$ & $123(35.5 \%)$ \\
\hline Grade $1-6$ & $6(5.9 \%)$ & $6(6.1 \%)$ & $11(12.1 \%)$ & $7(12.1 \%)$ & $22(6.4 \%)$ \\
\hline Parents and/or siblings with asthma & $64(62.1 \%)$ & $58(59.2 \%)$ & $54(58.7 \%)$ & $36(62.1 \%)$ & $153(43.6 \%)$ \\
\hline Any allergies reported $\dagger$ & $86(83.5 \%)$ & $75(76.5 \%)$ & $80(87.0 \%)$ & $44(75.9 \%)$ & $248(70.7 \%)$ \\
\hline \multicolumn{6}{|l|}{ Medication use } \\
\hline Any asthma medication last year & $82(79.6 \%)$ & $79(80.6 \%)$ & $83(90.2 \%)$ & $55(94.8 \%)$ & $299(85.2 \%)$ \\
\hline Adequate preventer medication use & $33(32.0 \%)$ & $28(28.6 \%)$ & $16(17.4 \%)$ & $15(25.9 \%)$ & $92(26.2 \%)$ \\
\hline \multicolumn{6}{|l|}{ Reliever medication } \\
\hline Any reliever medication use & $77(74.8 \%)$ & $72(73.5 \%)$ & $73(79.3 \%)$ & $52(89.7 \%)$ & $274(78.1 \%)$ \\
\hline Short-acting $\beta_{2}$ agonists & $76(73.8 \%)$ & $72(73.5 \%)$ & $73(79.3 \%)$ & $52(89.7 \%)$ & $273(77.8 \%)$ \\
\hline Anticholinergics & $3(2.9 \%)$ & $0(0.0 \%)$ & $4(4.4 \%)$ & $4(6.9 \%)$ & $11(3.1 \%)$ \\
\hline \multicolumn{6}{|l|}{ Preventer medication } \\
\hline Any preventer medication use & $33(32.0 \%)$ & $40(40.8 \%)$ & $41(44.6 \%)$ & $35(60.3 \%)$ & $149(42.5 \%)$ \\
\hline \multicolumn{6}{|l|}{ Steroidal preventers } \\
\hline ICS alone & $11(10.7 \%)$ & $15(15.3 \%)$ & $15(16.3 \%)$ & $14(24.1 \%)$ & $55(15.7 \%)$ \\
\hline Oral steroids & $3(2.9 \%)$ & $3(3.1 \%)$ & $2(2.2 \%)$ & $4(6.9 \%)$ & $12(3.4 \%)$ \\
\hline \multicolumn{6}{|l|}{ Non-steroidal preventers } \\
\hline Oral antileukotrienes & $1(1.0 \%)$ & $0(0.0 \%)$ & $0(0.0 \%)$ & $3(5.2 \%)$ & $4(1.1 \%)$ \\
\hline Inhaled cromones & $0(0.0 \%)$ & $0(0.0 \%)$ & $1(1.1 \%)$ & $1(1.7 \%)$ & $2(0.6 \%)$ \\
\hline \multicolumn{6}{|l|}{ Symptom controllers } \\
\hline LABAs & $1(1.0 \%)$ & $2(2.0 \%)$ & $0(0.0 \%)$ & $1(1.7 \%)$ & $4(1.1 \%)$ \\
\hline \multicolumn{6}{|l|}{ Combination therapy } \\
\hline Combination ICS and LABAs & $22(21.4 \%)$ & $25(25.5 \%)$ & $25(27.2 \%)$ & $21(36.2 \%)$ & $93(26.5 \%)$ \\
\hline
\end{tabular}

Values shown are number (\%).

ICS, inhaled corticosteroids; LABA, long-acting $\beta_{2}$ agonist.

*Data missing for five participants.

$\uparrow$ Allergic to food/dust/medicine/pets/pollens. 
Table 3 Lung function in community-based current asthma population by severity $(n=259 *)$

\begin{tabular}{|c|c|c|c|c|c|}
\hline $\begin{array}{l}\text { Lung function } \\
\text { measurements } \dagger\end{array}$ & $\begin{array}{l}\text { Intermittent } \\
(\mathrm{n}=\mathbf{7 9})\end{array}$ & $\begin{array}{l}\text { Mild persistent } \\
(\mathrm{n}=72)\end{array}$ & $\begin{array}{l}\text { Moderate persistent } \\
(\mathrm{n}=67)\end{array}$ & $\begin{array}{l}\text { Severe persistent } \\
(\mathrm{n}=41)\end{array}$ & $\begin{array}{l}\text { Current asthma total } \\
(\mathrm{n}=259)\end{array}$ \\
\hline $\mathrm{FEV}_{1}$ pre-BD (I) & 3.05 (2.93 to 3.17$)$ & 2.96 (2.83 to 3.08$)$ & 2.81 (2.68 to 2.94$)$ & 2.65 (2.48 to 2.82 ) & 2.99 (2.93 to 3.06$)$ \\
\hline $\mathrm{FEV}_{1}$ post-BD (I) & 3.20 (3.09 to 3.32 ) & 3.11 (2.99 to 3.22 ) & 3.03 (2.91 to 3.15 ) & 2.84 (2.68 to 2.99 ) & 3.17 (3.11 to 3.23$)$ \\
\hline FVC post-BD (I) & 4.20 (4.08 to 4.33 ) & 4.08 (3.95 to 4.21$)$ & 4.12 (3.98 to 4.25$)$ & 3.89 (3.72 to 4.06$)$ & $4.23(4.16$ to 4.29$)$ \\
\hline $\mathrm{FEV}_{1} / \mathrm{FVC}$ pre-BD (\%) & 74.4 (72.5 to 76.2 ) & 74.1 (72.1 to 76.0$)$ & 70.6 (68.6 to 72.7 ) & $70.0(67.4$ to 72.6$)$ & 72.6 (71.6 to 73.6$)$ \\
\hline $\mathrm{FEV}_{1} / \mathrm{FVC}$ post-BD (\%) & 76.2 (74.3 to 78.0$)$ & 76.5 (74.6 to 78.4$)$ & 74.1 (72.1 to 76.2 ) & 73.3 (70.7 to 75.8$)$ & 75.2 (74.3 to 76.1 ) \\
\hline
\end{tabular}

Values shown are mean $(95 \% \mathrm{Cl})$.

$\mathrm{BD}$, bronchodilator; $\mathrm{FEV}_{1}$, forced expiratory volume in $1 \mathrm{~s}$; FVC, forced vital capacity.

${ }^{*}$ Restricted to participants with current asthma with available lung function measurements.

$\dagger$ Adjusted for adequate preventer medication use, age, gender, smoking status, height and weight.

tDefined according to the ATS criteria and a positive response was defined as $\geqslant 12 \%$ improvement in $\mathrm{FEV}_{1}$ and an absolute improvement of $\geqslant 0.2 \mathrm{I}$.

preventer medication; however, this association attenuated after adjusting for "hospital admission for asthma ever" since participants with early-onset asthma were more likely to have been admitted to hospital for asthma (table 4). The associations between other determinants including gender, smoking, social class, and other allergic diseases with adequate preventer medication use were not found to be statistically significant.

\section{Adequacy of preventer medication use by severity}

For the group of participants with current asthma, approximately $71 \%(n=248)$ had persistent disease activity. While $45 \%$ ( $n=113$ ) of the participants with persistent asthma reported having used any kind of ICS, only 33\% $(n=82)$ used them on a regular basis. Of those taking regular ICS, not all were using adequate doses or combination treatment in relation to their severity. Approximately $28 \%$ of the participants with moderate persistent asthma and the $48 \%$ of participants with severe persistent asthma were using ICS regularly, whereas only $17 \%$ of the participants with moderate and $26 \%$ of the participants with severe persistent asthma were using defined minimal adequate preventer medication. Of participants with mild persistent asthma, 29\% were found to be taking adequate preventer medication.

When compared with the group of participants with mild persistent asthma, those with moderate persistent asthma had reduced odds of $57 \%$ for using adequate preventer medication (adjusted OR 0.43 (95\% CI 0.20 to 0.91), p = 0.027). The odds of adequate preventer medication use by participants with severe persistent asthma were also found to be lower (a reduction in 48\%) compared with the group of participants with mild persistent asthma, but this finding did not reach statistical significance (adjusted OR 0.52 (95\% CI 0.22 to 1.20 ), p = 0.123, table 4).

\section{Fixed airflow obstruction in adequate and inadequate preventer medication groups}

Lung function data were available for approximately $75 \%$ of the participants with current asthma. We analysed the association between lung function and severity by adequacy of preventer medication use. In the adequate medication group, those with severe asthma had lower $\mathrm{FEV}_{1}$ levels compared with the mild group. In addition, we found a statistically significant and progressive reduction in $\mathrm{FEV}_{1} / \mathrm{FVC}$ (from mild to severe) for the

Table 4 Factors associated with adequate preventer medication use among the community-based sample of current asthma participants $(\mathrm{n}=351$ )

\begin{tabular}{|c|c|c|c|c|c|c|}
\hline & \multirow{2}{*}{$\begin{array}{l}\text { Inadequate } \\
\text { preventer users } \\
(\mathrm{n}=259) \\
\mathrm{N}(\%)\end{array}$} & \multirow{2}{*}{$\begin{array}{l}\text { Adequate } \\
\text { preventer users } \\
\text { (n= 92) } \\
\mathrm{N}(\%)\end{array}$} & \multicolumn{2}{|c|}{$\begin{array}{l}\text { Unadjusted odds ratio for adequate } \\
\text { preventer medication use }\end{array}$} & \multicolumn{2}{|c|}{$\begin{array}{l}\text { Adjusted odds ratio for adequate } \\
\text { preventer medication use* }\end{array}$} \\
\hline & & & OR (95\% Cl) & p Value & OR (95\% Cl) & p Value \\
\hline Early-onset asthma patients & $118(45.6 \%)$ & $56(60.9 \%)$ & 1.86 (1.14 to 3.02$)$ & 0.012 & 1.35 (0.77 to 2.39$)$ & 0.299 \\
\hline \multicolumn{7}{|l|}{ Smoking status } \\
\hline Never & $109(42.1 \%)$ & $44(47.8 \%)$ & 1.00 & & 1.00 & \\
\hline Parents and/or siblings with asthma & $148(57.1 \%)$ & $64(69.6 \%)$ & $1.71(1.03$ to 2.85$)$ & 0.037 & $1.90(1.09$ to 3.32$)$ & 0.025 \\
\hline Any allergies reported & $206(79.50 \%)$ & $79(85.90 \%)$ & 1.56 (0.81 to 3.02$)$ & 0.184 & $1.45(0.70$ to 3.02$)$ & 0.349 \\
\hline \multicolumn{7}{|l|}{ Body mass index } \\
\hline Normal & $111(42.9 \%)$ & $31(33.7 \%)$ & 1.00 & & 1.00 & \\
\hline Overweight & $83(32.0 \%)$ & $37(40.2 \%)$ & $1.60(0.92$ to 2.78$)$ & 0.099 & $1.68(0.89$ to 3.16$)$ & 0.124 \\
\hline Obese & $65(25.1 \%)$ & $24(26.1 \%)$ & $1.32(0.72$ to 2.44$)$ & 0.373 & $1.34(0.68$ to 2.66$)$ & 0.389 \\
\hline Moderate persistent & $76(29.3 \%)$ & $16(17.4 \%)$ & $0.53(0.26$ to 1.05$)$ & 0.070 & $0.43(0.20$ to 0.91$)$ & 0.027 \\
\hline Severe persistent & $43(16.6 \%)$ & $15(16.3 \%)$ & $0.87(0.42$ to 1.82$)$ & 0.714 & $0.52(0.22$ to 1.20$)$ & 0.123 \\
\hline Intermittent & $70(27.0 \%)$ & $33(35.9 \%)$ & $1.18(0.65$ to 2.15$)$ & 0.593 & $1.06(0.55$ to 2.05$)$ & 0.868 \\
\hline
\end{tabular}

*Adjusted for gender, onset of asthma, smoking status, family history of asthma, other allergies, body mass index, utilisation of healthcare services last year, hospital admission for asthma ever and persistent asthma disease severity. 
Table 5 Degree of airflow obstruction in groups with persistent asthma by adequacy of treatment

\begin{tabular}{|c|c|c|c|c|c|}
\hline & \multirow{2}{*}{$\begin{array}{l}\text { Persistent } \\
\text { severity } \\
\text { groups }\end{array}$} & \multirow[b]{2}{*}{$\mathbf{N}(\%)^{*}$} & \multirow{2}{*}{$\begin{array}{l}\text { FEV }_{1} / \text { FVC post-BD } \dagger \\
\text { Mean }(95 \% \mathrm{Cl})\end{array}$} & \multicolumn{2}{|c|}{ Difference in mean $\mathrm{FEV}_{1} / \mathrm{FVC}$ post-BD } \\
\hline & & & & Difference (95\% CI) & p Value \\
\hline \multirow{3}{*}{$\begin{array}{l}\text { Inadequate } \\
\text { preventer users } \\
(\mathrm{n}=140)\end{array}$} & Mild & $50(35.7 \%)$ & 76.83 (74.32 to 79.34$)$ & 0.00 & \\
\hline & Moderate & $58(41.4 \%)$ & 74.15 (71.80 to 76.51$)$ & $-2.68(-6.14$ to 0.78$)$ & 0.128 \\
\hline & Severe & $32(22.9 \%)$ & 72.78 (65.95 to 79.62$)$ & $-4.80(-8.86$ to -0.74$)$ & 0.021 \\
\hline \multirow{3}{*}{$\begin{array}{l}\text { Adequate } \\
\text { preventer users } \\
(\mathrm{n}=40)\end{array}$} & Mild & $22(55.0 \%)$ & 75.05 (70.82 to 79.28$)$ & 0.00 & \\
\hline & Moderate & $9(22.5 \%)$ & 73.31 (66.54 to 80.09$)$ & $-1.74(-9.56$ to 6.08$)$ & 0.653 \\
\hline & Severe & $9(22.5 \%)$ & 77.66 (70.29 to 85.03 ) & $2.61(-6.13$ to 11.34$)$ & 0.547 \\
\hline
\end{tabular}

* Limited to participants with lung function data.

$\uparrow$ Adjusted for smoking, gender, age, height and weight.

tCalculated using multiple linear regression model for the two adequacy groups separately.

$\mathrm{BD}$, bronchodilator; $\mathrm{FEV}_{1}$, forced expiratory volume in $1 \mathrm{~s}$; FVC, forced vital capacity.

inadequately treated group but not for the adequately treated group (table 5).

\section{DISCUSSION}

Our aim was to evaluate the adequacy of preventer medication use by Australians with current asthma and its relationship to severity and lung function. To our knowledge, this is the first study to define adequacy of preventer medication using established national asthma guidelines and to assess how well asthma is being managed against such criteria. We found that the majority of patients with current asthma had persistent asthma, yet few were taking even minimally adequate preventer medication. Importantly, for those who were not taking adequate preventer therapy, their lung function measurements declined significantly with increasing severity while those taking adequate therapy had no such decline. Other allergic conditions and family history were observed to be strongly associated with increasing asthma severity by group. We found that, if participants had adult-onset asthma, had no family history and no history of hospital admission, they were more likely to be taking inadequate medications.

We investigated the implications of our findings for asthma outcomes and found a statistically significant fall-off in the post-BD $\mathrm{FEV}_{1} / \mathrm{FVC}$ ratio from mild to severe groups for the inadequate preventer users but not for the adequate preventer users. Although the numbers in these analyses were relatively small, we hypothesise that adequate use of preventer medication is protective against the progressive development of fixed airway obstruction associated with increasing asthma severity. This finding is supported by a recent randomised controlled trial of combination therapy versus formoterol alone for as-needed treatment, which found significantly better $\mathrm{FEV}_{1}$ for those on ICS/LABA combination therapy. ${ }^{23}$

A few participants with current persistent asthma reported not taking any medication for asthma in the last year. Of the three participants with severe persistent asthma who were not taking any asthma medication, one reported an emergency visit in the previous year. Lung function measurements were not available for this participant but were available for the other two; one had $\mathrm{FEV}_{1}$ post-BD $<80 \%$ predicted. This patient with severe persistent asthma and impaired lung function had asthma onset in childhood. Similarly, of the nine participants with moderate persistent asthma who were not taking any medication for asthma in the last year, one had $\mathrm{FEV}_{1}$ post-BD $<80 \%$. None of these patients reported emergency visits/ hospital admission in the last year.

We focused our evaluation of adequacy of preventer medication use on participants with persistent asthma only because, according to NAC guidelines, participants with intermittent asthma do not need to be on ICS. ${ }^{3}$ The proportion of adequate preventer medication use by participants with persistent asthma was approximately $24 \%$ (95\% CI $18 \%$ to $29 \%$ ). This is lower than the findings from Italy by De Marco et $a l^{12}$ who reported that $52 \%$ of patients with persistent asthma used adequate preventer medication. However, the mean age in the Italian study was 34 years compared with 44 years in our study population. It is perhaps surprising that younger patients may be adhering better to preventer medication than we have observed in our study. Patients' understanding of medication and adherence to asthma management are critically important, and hence it poses a major challenge for healthcare professionals to motivate patients to take preventer medications even when they are asymptomatic. ${ }^{24}$

Participants with mild persistent asthma were more likely to use adequate medication, and this is likely to be causal (that is, taking proper therapy leads to less severe disease and better outcomes). Even though we do not have information on disease severity for the participants at the beginning of preventer medication use, there is evidence to support this suggestion that regular use of adequate preventer medication for adequate periods of time results in patients shifting from "severe" to "less severe" disease activity. ${ }^{25} 26$ It is critical that patients using medication are followed up regularly over a considerable period and monitored iteratively using several outcome indices to assess control and management of their disease.

Our definition of adequacy of preventer medication is approximately equivalent to what a patient with asthma should be prescribed when being assessed by a GP for the first time. Many would need a subsequent increase of treatment to gain good control and perhaps future back-titration of ICS. Regardless, we thought it is reasonable to use the basal expected treatment to define "minimal adequacy" for the purposes of this study, recognising that this may well underestimate true needs.

Contrary to what might be expected, we observed a higher proportion of our adequate user group to have made use of healthcare services in the last year. The most likely explanation for this association is reverse causation (ie, those who made use of healthcare services were more likely to receive correct treatment advice and to adhere to treatment after an episode sufficient to attract medical intervention). We also found that the adequate preventer medication users were more likely to have asthma since childhood. This association was attenuated when we adjusted for "hospital admission for asthma ever", which suggests participants with early-onset asthma were more likely to use healthcare services. Hence, it is possible that the adequate preventer medication users in our study population had a more long standing and serious asthma condition and therefore they were more likely to make use of healthcare services. 
The availability of spirometric data were a major strength of our study. However, we did not include lung function as part of the severity classification, partly because it was not available for everyone but mainly because we wanted to assess spirometric measurements, especially degree of fixed airflow obstruction, as outcomes. Adequate preventer medication use was found to protect against the effects of progressive severity on development of fixed airflow obstruction. This should be an encouragement to both patients and practitioners to persist with good asthma management and especially appropriate medication titrated against disease severity criteria.

One limitation of our study is the lack of information on when or how frequently participants consult their doctors about their asthma. However, since those on preventer therapy would need regular prescriptions, we assume that there would have been frequent opportunities to intervene, either by the GP or pharmacist. A recent publication has emphasised how effective intervention from healthcare professionals can be, including improving quality of life, when an inadequate level of therapy relative to disease severity is noticed. ${ }^{27}$ Bereznicki et al show strong evidence that patients are prepared to change therapeutic practice under good professional guidance. ${ }^{27}$ This contrasts with published evidence that physicians have found it challenging to adhere to NAC guidelines, suggesting perceived limitations to such a regimented "one size fits all" approach. Some of these limitations include heterogeneity of asthma and symptom presentations, variations in response to treatment, lack of clearcut asthma diagnosis and cost of asthma management. ${ }^{28}{ }^{29}$ Furthermore, it has been demonstrated that emergency department physicians rarely use the NAC guidelines to assess acute asthma status and tend to underestimate the level of severity. ${ }^{30}$ Overall, the general picture seems to be one of many lost opportunities to intervene effectively in asthma care and to use core aspects of guidelines to assess asthma well and to initiate adequate levels of therapy accordingly.

\section{CONCLUSION}

Overall, the use of appropriate asthma therapy by our study population was found to be grossly inadequate. The groups at greatest risk were those with adult-onset persistent asthma, moderate or severe persistent asthma and those without a family history of asthma. Efforts for improvement should therefore be especially focused on these groups. Further research is needed on methods of improving patients' understanding of and adherence with effective medication use. Our current models of asthma care delivery need to be questioned and re-assessed. Patients with persistent symptomatic asthma, in particular, need more effective encouragement to use ICS and LABA combination therapy on a regular basis, and there are strategies that work. Adams et al ${ }^{31}$ reported that more positive interactions in terms of willingness of doctors to spend more time with and explain asthma management to patients appears to be associated with increased preventer use, independent of the level of asthma symptoms. Pharmacist interventions can also be successful. ${ }^{27}{ }^{32}$ Little specific attention has been given to the specific characteristics and needs of middle-aged patients with asthma, and yet they are a group especially vital to families, business and society in general. Our findings indicate that there is a large gap for the majority of patients with moderate to severe asthma between their current level of asthma management and optimal management, and that this is likely to have long-term consequences for their health.
Acknowledgements: We acknowledge the TAHS study participants and previous investigators. We thank three current TAHS investigators who are not co-authors of this manuscript (Dr James Markos, Associate Professor Paul Thomas and Dr Bruce Thomson) for their assistance with obtaining funds and data collection. Furthermore, we acknowledge all the respiratory scientists who collected data in the lung function laboratories of Tasmania, Victoria, Queensland and New South Wales as well as all the research interviewers and data entry operators.

Funding: This study was funded by the National Health and Medical Research Council of Australia, Clifford Craig Medical Research Trust of Tasmania and Victorian \& Tasmanian Asthma Foundations. RKK-R, MCM, SCD and JH are supported by the National Health and Medical Research Council.

Competing interests: None.

Ethics approval: The 2004 follow-up studies were approved by the Human Research Ethics Committee at the Universities of Melbourne, Tasmania and Monash, and Royal Brisbane Hospital.

Provenance and peer review: Not commissioned; externally peer reviewed.

\section{REFERENCES}

1. Anon. Variations in the prevalence of respiratory symptoms, self-reported asthma attacks, and use of asthma medication in the European Community Respiratory Health Survey (ECRHS). Eur Respir J 1996;9:687-95.

2. Australian Centre for Asthma Monitoring (ACAM). Asthma in Australia 2008. Canberra: Australian Institute of Health and Welfare (AlHW), 2008.

3. National Asthma Council. Asthma management handbook 2006. Melbourne: National Asthma Council, 2006.

4. National Asthma Education and Prevention Program. Guidelines for the diagnosis and management of asthma update on selected topics-2002. Expert Panel Report. J Allergy Clin Immunol 2002;110(5 Suppl):S141-219.

5. Global Initiative for Asthma (GINA). Global strategy for asthma management and prevention. 2007.

6. Ait-Khaled N, Enarson DA, Bissell K, et al. Access to inhaled corticosteroids is key to improving quality of care for asthma in developing countries. Allergy 2007;62:230-6.

7. Reeves MJ, Bohm SR, Korzeniewski SJ, et al. Asthma care and management before an emergency department visit in children in western Michigan: how well does care adhere to guidelines? Pediatrics 2006;117:S118-26.

8. Cowie RL, Underwood MF, Mack S. The impact of asthma management guideline dissemination on the control of asthma in the community. Can Respir J 2001;8(Suppl A): $41-5 A$.

9. Pauwels RA, Pedersen S, Busse WW, et al. Early intervention with budesonide in mild persistent asthma: a randomised, double-blind trial. Lancet 2003;361:1071-6.

10. Barnes PJ. Inhaled glucocorticoids for asthma. N Engl J Med 1995;332(13):868-75.

11. Gelfand EW. Advances in therapy for adult asthma. Clin Cornerstone 2008;8:62-75.

12. de Marco R, Cazzoletti L, Cerveri I, et al. Are the asthma guideline goals achieved in daily practice? A population-based study on treatment adequacy and the control of asthma. Int Arch Allergy Immunol 2005;138:225-34.

13. Matheson M, Wicking J, Raven J, et al. Asthma management: how effective is it in the community? Intern Med J 2002;32:451-6.

14. Wilson DH, Adams RJ, Appleton SL, et al. Prevalence of asthma and asthma action plans in South Australia: population surveys from 1990 to 2001. Med J Aust 2003;178:483-5.

15. Klomp H, Lawson JA, Cockcroft DW, et al. Examining asthma quality of care using a population-based approach. CMAJ 2008;178:1013-21.

16. Gibson HB, Silverstone H, Gandevia B, et al. Respiratory disorders in seven-year-old children in Tasmania. Aims, methods and administration of the survey. Med $\mathrm{J}$ Aust 1969;2:201-5.

17. Giles GG, Lickiss N, Gibson HB, et al. Respiratory symptoms in Tasmanian adolescents: a follow up of the 1961 birth cohort. Aust NZ J Med 1984;14:631-7.

18. Jenkins MA, Hopper JL, Flander LB, et al. The associations between childhood asthma and atopy, and parental asthma, hay fever and smoking. Paediatr Perinat Epidemiol 1993;7:67-76

19. Jenkins MA, Hopper JL, Bowes G, et al. Factors in childhood as predictors of asthma in adult life. BMJ 1994;309:90-3.

20. Wharton C, Dharmage S, Jenkins $M$, et al. Tracing 8,600 participants 36 years after recruitment at age seven for the Tasmanian Asthma Study. Aust NZ J Public Health 2006;30:105-10.

21. American Thoracic Society. Standardization of spirometry, 1994 update. Am J Respir Crit Care Med 1995;152:1107-36.

22. Gore CJ, Crockett AJ, Pederson DG, et al. Spirometric standards for healthy adult lifetime nonsmokers in Australia. Eur Respir J 1995;8:773-82.

23. Haahtela T, Tamminen K, Malmberg LP, et al. Formoterol as needed with or without budesonide in patients with intermittent asthma and raised NO levels in exhaled air: a SOMA study. Eur Respir J 2006;28:748-55.

24. Franks TJ, Burton DL, Simpson MD. Patient medication knowledge and adherence to asthma pharmacotherapy: a pilot study in rural Australia. Ther Clin Risk Manag 2005; 1:33-8.

25. Senthilselvan A, Lawson JA, Rennie DC, et al. Regular use of corticosteroids and low use of short-acting beta2-agonists can reduce asthma hospitalization. Chest 2005; 127:1242-51. 
26. Bateman ED, Clark TJ, Frith L, et al. Rate of response of individual asthma control measures varies and may overestimate asthma control: an analysis of the goal study. $J$ Asthma 2007:44:667-73.

27. Bereznicki BJ, Peterson GM, Jackson SL, et al. Pharmacist-initiated general practitioner referral of patients with suboptimal asthma management. Pharm World Sci 2008;30:869-75.

28. Price D, Thomas M. Breaking new ground: challenging existing asthma guidelines. BMC Pulm Med 2006:6(Suppl 1):S6.

29. Schneider A, Biessecker K, Quinzler R, et al. Asthma patients with low perceived burden of illness: a challenge for guideline adherence. J Eval Clin Pract 2007;13:846-52.
30. Powell CV, Kelly AM, Kerr D. Lack of agreement in classification of the severity of acute asthma between emergency physician assessment and classification using the National Asthma Council Australia guidelines (1998). Emerg Med (Fremantle) 2003:15:49-53.

31. Adams RJ, Weiss ST, Fuhlbrigge A. How and by whom care is delivered influences anti-inflammatory use in asthma: results of a national population survey. J Allergy Clin Immunol 2003:112:445-50.

32. Bereznicki BJ, Peterson GM, Jackson SL, et al. Data-mining of medication records to improve asthma management. Med J Aust 2008;189:21-5.

\section{Pulmonary puzzle}

\section{Orthopnoea and arm weakness}

\section{PULMONARY PUZZLE}

A 70-year-old Caucasian man was transferred back to New Zealand from an Italian hospital having been admitted there 6 weeks earlier with acute dyspnoea. There was no associated cough or fever and, despite antibiotic treatment, he remained dyspnoeic at rest with persistent orthopnoea. His left shoulder had been weak for over 10 years but he had recently noticed weakness in the right shoulder and arm. He had moderate chronic obstructive lung disease secondary to smoking. On examination he had a short neck, with limited range of movement in all directions, and a body mass index of 32 . His respiratory rate was $24 / \mathrm{min}$, oxygen saturation $80 \%$ on air. The chest was mildly hyperinflated but expansion was decreased and lung bases were dull to percussion with decreased breath sounds. There were no signs of pulmonary hypertension. Bilaterally, there was severe weakness in the shoulders (power grade $2 / 5$ on the right, $1 / 5$ on the left) and very mild weakness of arm flexion (power grade 5-/5). Tone was increased and reflexes brisk in all limbs. He was in asymptomatic urinary retention. An arterial blood gas on air was consistent with chronic type II respiratory failure ( $\mathrm{pH} 7.41, \mathrm{PCO}_{2} 66 \mathrm{~mm} \mathrm{Hg}$, $\mathrm{PO}_{2} 42 \mathrm{~mm} \mathrm{Hg}, \mathrm{HCO}_{3}{ }^{-} 41 \mathrm{mmol} / \mathrm{l}$ ); spirometric tests showed a $52 \%$ reduction in his vital capacity in the lying position compared with sitting $(0.711$ to 1.461$)$ and the chest radiograph showed bilateral loss of lung volume with elevated hemidiaphragms. A sniff test showed bilateral diaphragmatic paralysis without paradoxical movement and serum creatine kinase levels were normal. A CT scan showed moderate bibasal atelectasis only. MRI of the neck demonstrated extensive vertebral abnormalities in the cervical spine (fig 1).

\section{QUESTION}

What is the diagnosis and what further investigations are required?

See page 1069 for answers

\section{H K Chen, ${ }^{1}$ D Jardine, ${ }^{2}$ L Beckert ${ }^{1}$}

${ }^{1}$ Department of Respiratory Medicine, Christchurch Hospital, Christchurch, New Zealand;

${ }^{2}$ Department of General Medicine, Christchurch Hospital, Christchurch, New Zealand

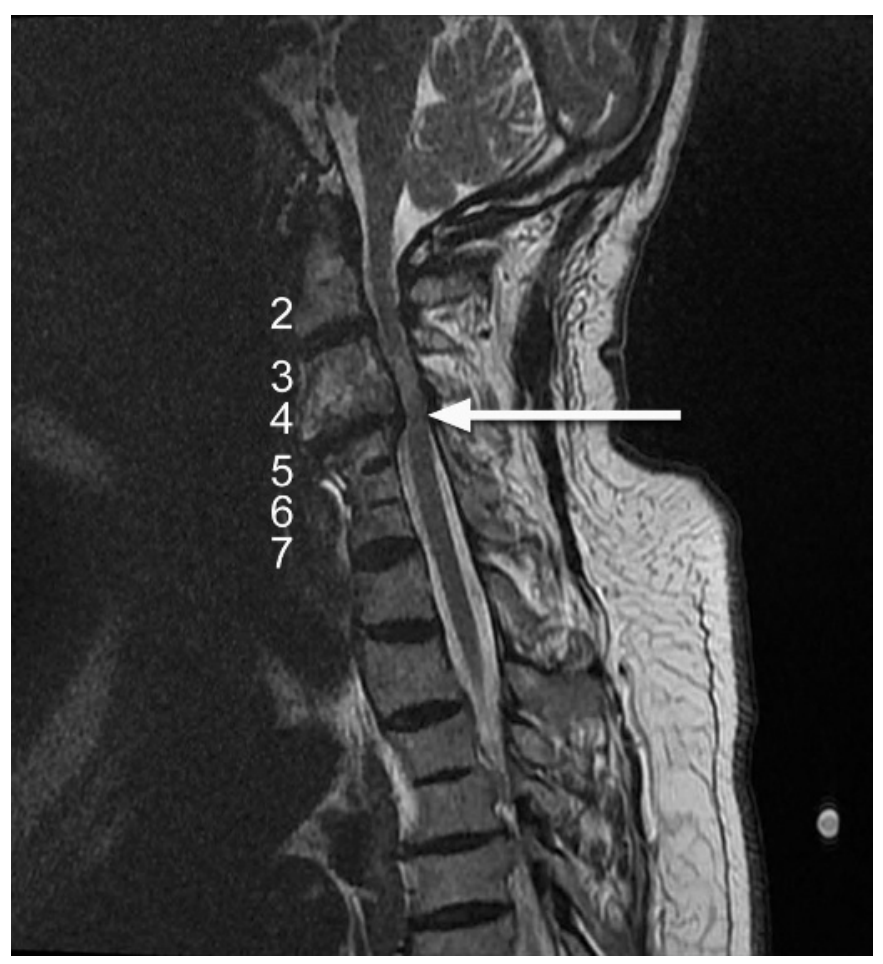

Figure $1 \mathrm{~T} 2 \mathrm{MRI}$ of sagittal cervical spine showing congenital synostosis of the $\mathrm{C} 3 / \mathrm{C} 4$ and $\mathrm{C} 5 / \mathrm{C} 6 / \mathrm{C} 7$ vertebrae consistent with KlippelFeil syndrome. The C3/4 disc-osteophyte complex is causing severe compression to the cord (arrow) and myelomalacia above this level. The relevant vertebral bodies are numbered.

Correspondence to: D L JardineGeneral Medicine, Christchurch Hospital, Christchurch 8011, New Zealand; david.jardine@cdhb.govt.nz

Acknowledgements: We thank Tony Goh for his interpretation of the MRI studies and Grant Carroll for undertaking and interpreting the nerve conduction studies. The figure was prepared by The Medical Illustrations Department, Christchurch Hospital.

Competing interests: None.

Patient consent: Obtained.

Thorax 2009;64:1031. doi:10.1136/thx.2009.121632 